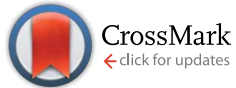

Cite this: RSC Adv., 2017, 7, 13997

Received 11th January 2017

Accepted 20th February 2017

DOI: $10.1039 / c 7 r a 00464 h$

rsc.li/rsc-advances

\section{Gum karaya (Sterculia urens) stabilized zero-valent iron nanoparticles: characterization and applications for the removal of chromium and volatile organic pollutants from water $\dagger$}

\author{
Vellora Thekkae Padil Vinod, ${ }^{\text {*a }}$ Stanisław Wacławek, ${ }^{a}$ Chandra Senan, ${ }^{\mathrm{b}}$ \\ Jaroslav Kupčik, ${ }^{c}$ Kristýna Pešková, ${ }^{a}$ Miroslav Černík ${ }^{* a}$ and H. M. Somashekarappa ${ }^{d}$
}

This paper illustrates a method for the stabilization of nanoscale zerovalent iron (NZVI) suspensions with a "green" biopolymer, Gum Karaya (GK). The stability, sedimentation, aggregation behavior and reactivity towards Cr(vI) and volatile organic compounds using NZVI-GK (GK stabilized NZVI) and bare NZVI, were assessed. The stabilization mechanism of NZVI-GK was demonstrated using ATR-FTIR, XRD, XPS, TEM, SEM, TGA and particle size analysis. The NZVI-GK nanoparticle suspension was found to be stable for at least three months, suggesting a superior stability rendering property of GK which forms a scaffold to prevent NZVI from aggregating. Batch experiments, centred on $\mathrm{Cr}(\mathrm{VI})$ reduction and degradation of volatile organic compounds, confirmed that NZVI-GK was more reactive than bare NZVI. Furthermore, XPS and ICP-MS results revealed that $\mathrm{Cr}(\mathrm{VI})$ was reduced to $\mathrm{Cr}(\mathrm{III})$ by $\mathrm{NZVI-GK}$ and the remaining $\mathrm{Cr}$ (III) in solution was adsorbed onto GK, thereby completely removing chromium from the contaminated water. Our study suggests that an important role is played due to the attributes of GK (which include nontoxicity, biodegradability and cost-effectiveness) in conjunction with the ability of NZVI to remove all chromium viz. [Cr(VI) and $\mathrm{Cr}(\mathrm{III})]$ coupled with the total degradation and removal of VOCs (cis-1,2dichloroethene, perchloroethene and trichloroethene) from water.

\section{Introduction}

Nanoscale Zero-Valent Iron (NZVI) has been studied as a prospective innovative technology for the remediation of contaminated water and soil for decades. The high reactivity of NZVI towards a broad range of contaminants such as chlorinated organic compounds (chlorinated methanes, ethanes, ethenes, chlorinated aromatic compounds and pesticides); heavy metals; radioactive nuclides; nitro aromatic compounds; nitrates; dyes and phenol has been reported extensively. ${ }^{\mathbf{1 - 3}}$

The major problems facing remediation technology employing NZVI are its susceptibility to aggregation, limited mobility in the subsurface environment and longevity under such conditions. ${ }^{3}$ To be effectively utilised in aquifer (in situ)

\footnotetext{
${ }^{a}$ Centre for Nanomaterials, Advanced Technologies and Innovation, Technical University of Liberec, Studentská 1402/2, 46117 Liberec, Czech Republic. E-mail: vinod.padil@tul.cz; vinodvellorathekkaepadil@gmail.com; miroslav.cernik@tul.cz

${ }^{b}$ Centre for Water Soluble Polymers, Applied Science, Engineering and Computing, Glyndwr University, Wrexham LL11 2AW, Wales, UK

'Institute of Inorganic Chemistry of the Czech Academy of Sciences, v. v. i., Husinec-̌̌ež, 1001, 25068 Řež, Czech Republic

${ }^{d}$ CARRT, Mangalore University, India-574 199

$\dagger$ Electronic supplementary information (ESI) available. See DOI: 10.1039/c7ra00464h
}

remediation, NZVI should remain in suspension for long periods, allowing for slurry preparation, handling and injection into the contaminated site. Furthermore, mobility of NZVI's in the subsurface is the key element governing effective remediation of the contaminated site. However, many studies have demonstrated that the stability and mobility of NZVI was restricted due to the strong tendency of NZVI particles to aggregate in aqueous environments which resulted in lower specific surface area and subsequently in reduced reactivity., ${ }^{\mathbf{4 , 5}}$ Additionally, the mobility of NZVI can be constrained due to interaction between iron particles and soil grains, causing NZVI deposition onto the porous matrix. ${ }^{3}$ Many studies have proposed solutions for overcoming the problems of stability and mobility of NZVI in porous media and the requirement is for modification of the surface properties of NZVI using a combination of natural and engineered polymers, together with surfactants, thereby enhancing colloidal stability and NZVI mobility in porous media. ${ }^{6,7}$ Various natural and synthetic polymeric materials such as guar gum, xanthan gum, starch, agar agar, poly(acrylic acid) (PAA), Tween-20, polyelectrolytes (polystyrene sulphonate and polyaspartate), organic matter and CMC have been used to improve the stability, reactivity and mobility of NZVI in porous media. ${ }^{8-16}$ These polymers can interact with NZVI particles and prevent aggregation by 
reducing particle-particle attractive forces which can increase repulsion between the particles and the porous medium. ${ }^{3}$ Important properties such as stabilizing capacity and shear thinning exhibited by xanthan gum deemed the latter to be a suitable material for NZVI particle mobility and aggregation studies. ${ }^{17}$ The first applications of NZVI in contaminated fields were conducted by injecting non-stabilized particles at a concentration of $1 \mathrm{~g} \mathrm{~L}^{-1}$ but the results were unsatisfactory. ${ }^{18}$ The enhancement of electrosteric and kinetic properties of NZVI in the presence of both guar gum and xanthan gum have been reported. ${ }^{\mathbf{8}, 12}$ Modification and stabilization of NZVI using natural gums such as guar gum and xanthan gum were shown to be effective in improving colloidal stability, reactivity and mobility of NZVI. ${ }^{3}$ Furthermore, the viscosity of the overall mixture was found to have increased at higher concentrations of guar gum, thereby limiting sedimentation of NZVI and hindering particle aggregation by virtue of reducing the frequency of collisions among particles, owing to the shearthinning behavior of this gum. ${ }^{17}$

Gum Karaya (GK), a natural hydrocolloid gum obtained from the karaya tree has been used as a food additive and pharmaceutical ingredient for centuries. The importance of polymeric surfactants based on natural hydrocolloids is increasing due to their non-toxicity, biodegradability, availability and superior physico-chemical properties. GK (Sterculia urens), a rhamnogalacturonoglycan (pectic) type gum, is a partially acetylated polysaccharide, with a branched structure and a high molecular mass of $16 \times 10^{6} \mathrm{Da}^{19,20} \mathrm{GK}$, a commercial tree gum, is widely used as a food additive and pharmaceutical ingredient, as well as an agent for promoting emulsification, stabilization and thickening. ${ }^{19}$ The properties, structural arrangement and composition of GK solutions have been studied extensively, ${ }^{21,22}$ neutral sugars such as rhamnose, galactose, arabinose and acidic sugar moieties of uronic acids (galacturonic and glucuronic) being the main constituents. ${ }^{23}$ The presence of various functional groups (viz. sugars, proteins, lipids and tannin) are indicative of its usefulness as a natural bio-sorbent. ${ }^{23,24}$ Hydroxyl $(-\mathrm{OH})$ groups present in arabinose and rhamnose and carboxylic $(\mathrm{COOH})$ groups found in glucuronic acid play a crucial role in the binding of toxic metal ions $\left(\right.$ e.g. $\left.\mathrm{Hg}^{2+}\right)$ from aqueous solutions to the gum biopolymer structure. ${ }^{25}$

For effective contaminant remediation by NZVI, it is imperative that a stable, well dispersed and highly concentrated NZVI suspension (with enhanced mobility and reactivity in the porous media) is developed. To achieve these objectives, extensive laboratory experiments and rigorous field tests should be performed. The major points to be addressed in this study relate to selecting the most appropriate stabilizing agent. Adoption of a stabilization approach will help to reduce particle aggregation; aid the development of biodegradable and environmentally-friendly polymeric surfactants as stabilizing agents and lead to an improvement in the mobility and reactivity of NZVIs.

In light of the above perspectives, a natural, tree-based polymer such as GK was chosen as the stabilizing agent for NZVI. A detailed investigation of the NZVI-GK composite was carried out in order to evaluate the changes in stability, particle aggregation and reactivity towards $\mathrm{Cr}(\mathrm{vI})$ and volatile organic compounds (VOCs) viz. cis-1,2-dichloroethene (cis-1,2-DCE), perchloroethene (PCE) and trichloroethene (TCE) that are present in ground water from the Pisecna location (Czech Republic).

\section{Materials and methods}

\subsection{Materials}

Commercial gum karaya (GK), $\mathrm{K}_{2} \mathrm{CrO}_{4}, 1,5$-diphenylcarbazide, $\mathrm{HCl}, \mathrm{HNO}_{3}$ and $\mathrm{NaOH}$ were purchased from Sigma-Aldrich, USA. Deionised water $\left(18.2 \mathrm{M} \Omega \mathrm{cm}^{-1}\right)$ was prepared by an ELGA purelab flex system (ELGA, Veolia Water, Marlow, UK) and used in all experiments. NANOFER STAR (air - stable NZVI powder consisting of an iron oxide layer) was purchased from NANO IRON, s.r.o., Czech Republic. Polluted groundwater was taken from the Pisecna location (Czech Republic). Water from the location was taken from a depth of 10 meters beneath the ground surface; collected in 20 litre cylinders; transferred to the laboratory and stored at $4{ }^{\circ} \mathrm{C}$ under anoxic conditions. The contaminant composition was determined prior to the tests; (cis-1,2-DCE: $378 \mu \mathrm{g} \mathrm{L}^{-1}$; PCE: $18530 \mu \mathrm{g} \mathrm{L}^{-1}$; TCE: $13040 \mu \mathrm{g} \mathrm{L}^{-1}$, respectively). ${ }^{26}$

\subsection{Purification of gum karaya (GK)}

GK powder was purified by dissolution, filtration and dialysis as reported earlier. ${ }^{\mathbf{2 0}}$ The estimated molar mass distributions (weight average, $M_{\mathrm{w}}$; number average, $M_{\mathrm{n}}$ and $z$-average, $M_{z}$ ) and rms radius moments $\left(R_{\mathrm{n}}, R_{\mathrm{w}}\right.$ and $R_{z}$, all in $\left.\mathrm{nm}\right)$ of GK $(1.827 \times$ $10^{6} \mathrm{~g} \mathrm{~mol}^{-1}$ ) was determined using GPC/MALLS and fitted with first-order polynomials using the Zimm method as reported. ${ }^{20}$

\subsection{Activation of NANOFER STAR}

Nanoparticles of zero-valent iron, produced by unique technology of the NANO IRON, s.r.o. company, exhibited an average particle size of 50-100 nm; an average surface area of $20-25 \mathrm{~m}^{2} \mathrm{~g}^{-1}$; a narrow particle size distribution of $20-100 \mathrm{~nm}$ and a high iron content in the range of $80-90 \mathrm{wt} \%$. NANOFER STAR (NF) was produced and delivered in a form of dry powder with a surface protective oxide shell that required activation prior to application. Standard activation protocols are based on preparation of the $20 \%$ slurry ( $20 \mathrm{~g}$ of air-stable NZVI NF STAR dispersed in 100 $\mathrm{mL}$ of distilled water). The whole mixture was homogenized and dispersed for 2 min using a IKA ULTRA-Turrax basic T 25 powder mixer at $15000 \mathrm{rpm}$ and left for approximately 48 hours at room temperature without additional mixing. The solution was mixed again as described above. After the activation process, the slurry was diluted to obtain the final concentration for the experiment. During activation, the NANOFER STAR's surface washes and disintegrates and in so doing, the $\mathrm{Fe}(0)$ becomes available for reduction.

\subsection{Preparation of NZVI-GK nanoparticle suspension}

Activated NZVI particles $\left(200.0 \mathrm{~g} \mathrm{~L}^{-1}\right)$ with purified GK $\left(20.0 \mathrm{~g} \mathrm{~L}^{-1}\right)$ were mixed in various wt/wt ratios $(1: 1,1: 2$ and $1: 3$ of GK and NZVI, respectively) to produce NZVI-GK 
suspensions. The latter were again blended for $10 \mathrm{~min}$ and finally sonicated for the same duration. The solution $\mathrm{pH}$ of the NZVI-GK slurry was adjusted with $1.0 \mathrm{~N} \mathrm{NaOH}$ or $\mathrm{HCl}$, respectively.

\subsection{Characterization of NZVI-GK nanoparticles}

2.5.1. Morphological analysis by SEM. The composition and morphology of GK, NZVI, NZVI-GK and Cr/NZVI-GK (Cr adsorbed onto NZVI-GK) was studied using a scanning electron microscope with a beam current ( 12 to $40 \mathrm{nA}$ ) and acceleration voltage $(0.02$ to $30 \mathrm{kV})$ in conjunction with a complete detection system comprising in-lens energy and angle selective backscatter' detectors (EsB); 4-quadrant solid-state backscatter detector (AsB) and conventional secondary electron detector (Everhart-Thornley) (ZEISS, Ultra/Plus, Germany). The specimens were permanently mounted onto stubs using slow-drying araldite or silver dag. The stub with the specimen was then sputter coated with a thin layer of gold to make the specimens conductive under high vacuum conditions. The processed specimens were subjected to SEM evaluation and EDXA analysis was conducted to determine the presence of various elements in GK, NZVI-GK and Cr/NZVI-GK nanoparticles.

2.5.2. Transmission electron microscopy (TEM) and HRTEM analysis. TEM and HR-TEM (high resolution transmission electron microscopy) images were recorded using a transmission electron microscope (JEOL, Japan) to characterize the nanostructures and determine particle distribution. The samples were prepared on standard copper TEM grids covered with thin carbon foil. Drops of NZVI or NZVI-GK were dispersed in $1 \mathrm{~mL}$ of isopropanol using ultrasound for $10 \mathrm{~min}$. In both cases, a drop of solution was gently spread onto the upper surface of the carbon covered copper TEM grid.

2.5.3. Particles size analysis. The size distributions of GK and NZVI-GK nanoparticles in aqueous media were measured using the centrifugal particle sedimentation (CPS) by the Disc Centrifuge technique (DC24000UHR, CPS Instruments Inc., USA). Measurements were made at a disc rotation speed of $5700 \mathrm{rpm}$ and particle sedimentation was performed in sucrose over a $8-24 \%(w / w)$ density gradient. Prior to each sample measurement, the instrument was calibrated using PVC nanosphere standards (476 $\mathrm{nm}$ particle size) which is applicable to a large range of particle sizes and densities. The concentrations of the dispersed NZVI nanoparticles in the solution were estimated using ICP-MS analysis.

2.5.4. Zeta potential analysis. The zeta potential values of GK, NZVI and NZVI-GK nanoparticles were determined in freshly prepared suspensions by means of a Zetasizer ZS (Malvern Instruments Ltd, UK). Each measurement was carried out (ten runs) with autocorrelation functions of 10 seconds. The results for each sample were obtained from triplicate measurements.

2.5.5. Batch experiments $\mathrm{Cr}(\mathrm{III}), \mathrm{Cr}(\mathrm{vI})$, total $\mathrm{Cr}$ and VOCs (cis-1,2-DCE, PCE and TCE). All the batch experiments were carried out in three-neck flasks at $20{ }^{\circ} \mathrm{C}$, placed in a shaking water bath incubator under an atmosphere of nitrogen. To each flask, $300 \mathrm{~mL}$ solutions containing various amounts of bare
NZVI or NZVI-GK in $1: 1,1: 2$ and $1: 3$ ratios of wt/wt concentrations of $200 \mathrm{~g} \mathrm{~L}^{-1}$ (NZVI) to $20 \mathrm{~g} \mathrm{~L}^{-1}$ (GK) and various amounts of $\mathrm{Cr}(\mathrm{vI})$ from $5.0-100 \mathrm{mg} \mathrm{L}^{-1}$ were added. The suspensions was stirred vigorously for finite reaction periods (10 min to $3 \mathrm{~h}$ ) with the $\mathrm{pH}(2-10)$ being adjusted by $0.1 \mathrm{M} \mathrm{HCl}$ or $\mathrm{NaOH}$. Aliquots of the samples were taken at designated time intervals, centrifuged and filtered using $0.45 \mu \mathrm{m}$ filters. The ensuing filtered solutions were later analyzed.

2.5.6. Kinetic experiments $\mathrm{Cr}$ and VOCs. To determine the reaction kinetics of $\mathrm{Cr}(\mathrm{vI})$ removal, various concentrations of NZVI $\left(0.25,0.50\right.$ and $\left.1.00 \mathrm{~g} \mathrm{~L}^{-1}\right)$ were added to $50 \mathrm{~mL}$ of water spiked with potassium chromate $[\mathrm{Cr}(\mathrm{vI})$ initial concentration $=$ $\left.10 \mathrm{mg} \mathrm{L}^{-1}\right]$. At selected time intervals $(2.5,5,10,20$ and $30 \mathrm{~min})$, samples were removed, filtered and tested for residual Cr(total) and $\mathrm{Cr}(\mathrm{vI})$. In order to monitor the decontamination of selected VOCs (PCE, TCE and cis-1,2-DCE) in groundwater from Pisecna, air-tight $50 \mathrm{~mL}$ reactors were used and a constant mixing rate of $200 \mathrm{rpm}$ adopted. GK, NZVI and NZVI-GK were added at dosages of $0.5,5$ and $5 \mathrm{~g} \mathrm{~L}^{-1}$, respectively. Subsequently, at selected time intervals, $7 \mathrm{~mL}$ aliquots of reacted solutions were filtered and analysed.

2.5.7. $\mathrm{Cr}(\mathrm{VI}), \mathrm{Cr}(\mathrm{III})$ \& total $\mathrm{Cr}$ analysis. In order to determine the reduction capacity of bare NZVI and NZVI-GK nanoparticles, appropriate amounts of each sample with the same iron content (to be determined by ICP-AES analysis of NZVI and NZVI-GK samples) were added to $10-100 \mathrm{mg} \mathrm{L}^{-1}$ of $\mathrm{Cr}(\mathrm{vI})$ containing solutions. The reduction of $\mathrm{Cr}(\mathrm{vI})$ was performed under different $\mathrm{pH}$ (1.0 to 5.0 ) conditions; various reaction times (10-180 $\mathrm{min}$ ); and at a temperature at $20{ }^{\circ} \mathrm{C}$. The $\mathrm{pH}$ of the reaction solutions were adjusted with $1.0 \mathrm{~N} \mathrm{HCl}$. During the reaction, small amounts (approximately $2.0 \mathrm{~mL}$ ) were withdrawn at each time interval and analysed for $\operatorname{Cr}(\mathrm{vI})$. The $\mathrm{Cr}(\mathrm{VI})$ concentration of the solutions (sampled at the initial and final reaction times) were determined at a wavelength of $540 \mathrm{~nm}$, using a UV-Vis spectrophotometer (Cintra 202 UV-VIS spectrophotometer, GBC, Australia) in accordance with the 1,5-diphenylcarbazide method. ${ }^{27,28}$ Total Cr was also analysed employing the ICP-MS method (NexION 300 Q, PerkinElmer, USA). Cr(III) concentrations in solution were estimated by subtracting the residual $\mathrm{Cr}(\mathrm{vI})$ concentrations from the residual total $\mathrm{Cr}$ concentrations. ${ }^{27}$

2.5.8. Volatile organic compounds (PEC, TCE and cis-1,2 DCE) analysis. The dechlorinating of VOCs [perchloroethene (PCE), trichloroethene (TCE) and cis-1,2-DCE (cis-1,2-dichloroethene)] from Pisecna samples by GK, NZVI and NZVI-GK (0.5, 5 and $5 \mathrm{~g} \mathrm{~L}^{-1}$, respectively) were investigated in an airtight environment using $50 \mathrm{~mL}$ serum bottles sealed with Teflonlined rubber septa and aluminium crimp caps. The bottles were incubated in an orbital shaker $(200 \mathrm{rpm})$ at room temperature, housed in the dark. Control experiments were also carried out without GK, NZVI and NZVI-GK. At selected time intervals, 3.5 aliquots of reacted sample were withdrawn using a gas tight syringe, immediately filtered through $0.22 \mu \mathrm{m}$ filters and transferred to headspace vials.

In addition, the vials were transferred to the CombiPAL autosampler (CTC Analytics AG, Switzerland) of the Varian CP-3800 Gas Chromatograph (GC)/Saturn 2200 ion trap mass spectrometer. The headspace analytical technique was used for determination of 
VOCs. Samples were incubated in the autosampler at defined temperatures, times and agitation intensities. The autosampler conditions adopted were as follows: syringe temperature, $90{ }^{\circ} \mathrm{C}$; agitator temperature, $80{ }^{\circ} \mathrm{C}$ and incubation time of the sample in the agitator, $5 \mathrm{~min}$. After the establishment of interfacial (vapourliquid) equilibrium, the samples were withdrawn by the autosampler needle from the headspace vials and injected into the GC system. The capillary column used $(60 \mathrm{~m}$ in length, $0.32 \mathrm{~mm}$ in diameter and $1.8 \mu \mathrm{m}$ in film thickness) was equipped with a VF$624 \mathrm{~ms}$ and procured from Agilent Technologies. The temperature programme of the $\mathrm{GC}$ commenced at $50{ }^{\circ} \mathrm{C}(4 \mathrm{~min})$ at a heating rate of $8{ }^{\circ} \mathrm{C} \mathrm{min}^{-1}$. The final temperature of $220^{\circ} \mathrm{C}$ was maintained for $4.75 \mathrm{~min}$. Helium was employed as the carrier gas with a flow rate of $1.0 \mathrm{~mL} \mathrm{~min}^{-1}$. Calibration was undertaken utilizing an external standard method by preparing known concentrations of VOCs. To accomplish this, EPA 502/524.2 VOC Mix $200 \mu \mathrm{g} \mathrm{mL}^{-1}$ in methanol (Sigma-Aldrich Company, USA) was used. Calibration was performed by measuring the calibration solutions at a minimum of five concentration levels in the range of linear response of the detector.

2.5.9. XRD analysis. X-ray diffraction spectra was recorded on an X-ray diffraction spectrometer (Bruker, AXS/8, Berlin, Germany). The diffraction spectra were obtained using $\mathrm{Cu}-\mathrm{K} \alpha$ radiation $(40 \mathrm{kV}, 60 \mathrm{~mA})$. Diffractograms were run at a scanning speed of $20 \mathrm{~min}^{-1}$ and chart speed of $20 / 2 \mathrm{~cm}$ per $2 \theta$.

2.5.10. X-ray photoelectron spectroscopy (XPS). The surface composition of the GK and NZVI-GK nanoparticles and the reduction of $\mathrm{Cr}(\mathrm{vI})$ using NZVI-GK nanoparticles were analyzed with an X-ray photoelectron spectroscope (Kratos AXIS 165, Alberta, Canada). XPS spectra were obtained by applying a $\mathrm{Mg}-\mathrm{K} \alpha$ $(1253.6 \mathrm{eV})$ energy source of monochromatic radiation operating at $15 \mathrm{kV}$ and $10 \mathrm{~mA}$. The residual pressure in the analysis chamber was $5 \times 10^{-10}$ Torr $\left(6.66 \times 10^{-8} \mathrm{~Pa}\right)$. Survey scans were recorded in the binding energy range $0-1100 \mathrm{eV}\left(1.76 \times 10^{-16} \mathrm{~J}\right)$ with a pass-energy of $80 \mathrm{eV}\left(1.28 \times 10^{-17} \mathrm{~J}\right)$. The XPS spectra were deconvoluted using the MultiPak (Ulvac - PHI, Inc.) software along with a Shirley background subtraction, a Gaussian sum function and an iterative least-squares optimization algorithm. All binding energy (BE) values were referenced to the adventitious C 1 s peak at $284.80 \mathrm{eV}$.

2.5.11. ATR-FTIR spectrometry. FTIR spectra were obtained using a spectrophotometer (NICOLET IZ10, Thermo Scientific, USA). The instrument was equipped with a single reflection single angle $45^{\circ}$ horizontal ATR accessory. Spectra were generated with a resolution of $4 \mathrm{~cm}^{-1}$, spanning the $4000-400 \mathrm{~cm}^{-1}$ wavenumber range using a germanium ATR crystal.

2.5.12. Thermogravimetric (TG) analysis. Thermal stability and composition of the GK and NZVI-GK were determined using Mettler Toledo apparatus: TGA/SDTA851e. The experimental atmosphere was nitrogen at a flow rate of $20 \mathrm{~mL} \mathrm{~min}{ }^{-1}$ and the samples were heated from 30 to $800{ }^{\circ} \mathrm{C}$.

\section{Results and discussion}

\subsection{SEM/EDX analysis}

Morphologies of GK, NZVI, NZVI-GK as well as Cr adsorbed NZVI-GK were analyzed using SEM and their corresponding
EDX profiles are presented in Fig. 1 which shows the EDX analysis of GK representing the various elements present (viz. $\mathrm{Ca}, \mathrm{Na}, \mathrm{Mg}, \mathrm{Al}$ and $\mathrm{Cl}$ ) in GK. Lyophilized GK, with observable fibrous structures (inset Fig. 1a), can easily interact with NZVI to form a NZVI-GK composite (Fig. 1c) and NZVI particles were found inside the network of GK scaffolds. The NZVI particles (20-100 $\mathrm{nm}$ in diameter) with particular characteristics were observed (Fig. 1b). The EDXA profile shows Fe peaks (Fig. 1c) while the Cr/NZVI-GK composite exhibits extremely rough surfaces, possibly due to interaction of NZVIGK with Cr to bring about a surface precipitation reaction between chromate and iron ions (Fig. 1d). The EDX sketch furnishes the adsorbed Cr peaks on the surface of NZVI-GK (inset Fig. 1d).

\subsection{TEM and HRTEM analysis}

The core-shell structure consisting of a core layer of $\mathrm{Fe}^{0}$ and a shell layer of iron oxides was observed in bare NZVI (Fig. 2c). Fig. 2b clearly indicated that NZVI particles were stabilized on the GK network structure, and that the particle size was $~ 20-$ $100 \mathrm{~nm}$. Compared with bare NZVI particles, NZVI on the GK polymer dispersed homogeneously. These effects were due to the inhibiting effect of GK on NZVI aggregation. Fig. 1b showed that the NZVI particles were not simply mixed or blended with GK. Instead, they were protected on the GK network structure as depicted in Fig. 5. Selected area diffraction patterns (inset Fig. 2a \& b) were suggested the formation of crystalline structures of NZVI in the bare NZVI as well as in NZVI-GK composite. A TEM image of the NZVI particles revealed that bare NZVI was aggregated with iron nanoparticles, resulting from magnetic interactions between NZVI particles (Fig. 2a). Association of GK with NZVI particles reduced the magnetic interactions between them. The HRTEM image of the NZVI particles (Fig. 2c) illustrated an apparent iron oxide layer formed on the surface of the bare NZVI. However, no distinct iron oxide layer could be discerned on the surface of the NZVI-GK (Fig. 2d). Clear lattice fringes in the HRTEM images of NZVI-GK (Fig. 2d) implied the generation of crystalline NZVI particles.

\subsection{Particle size analysis}

Particle size distributions of bare NZVI and NZVI-GK analyzed by CPS are presented in Fig. 3. The mean particle sizes of bare NZVI particles were found to be 770, 920, 1090, 1260 and $2010 \mathrm{~nm}$, respectively for the blank and the samples after one week, two weeks, one month and three months storage at room temperature (Fig. 3a). However, the comparative mean particle sizes of NZVI-GK were 730, 730, 870, 870 and $1240 \mathrm{~nm}$, respectively for the blank and the samples (stored for and under identical conditions to the ones mentioned above) (Fig. 3b). Clearly, the NZVI-GK appeared to be more stable in comparison with the bare NZVI particles and the particle size measurements corresponded with TEM analytical data (Fig. 2a and b). Particle size measurement data obtained by CPS methods and TEM analysis were found to vary by $\pm 10-20 \%$, as reported earlier. ${ }^{28}$ 

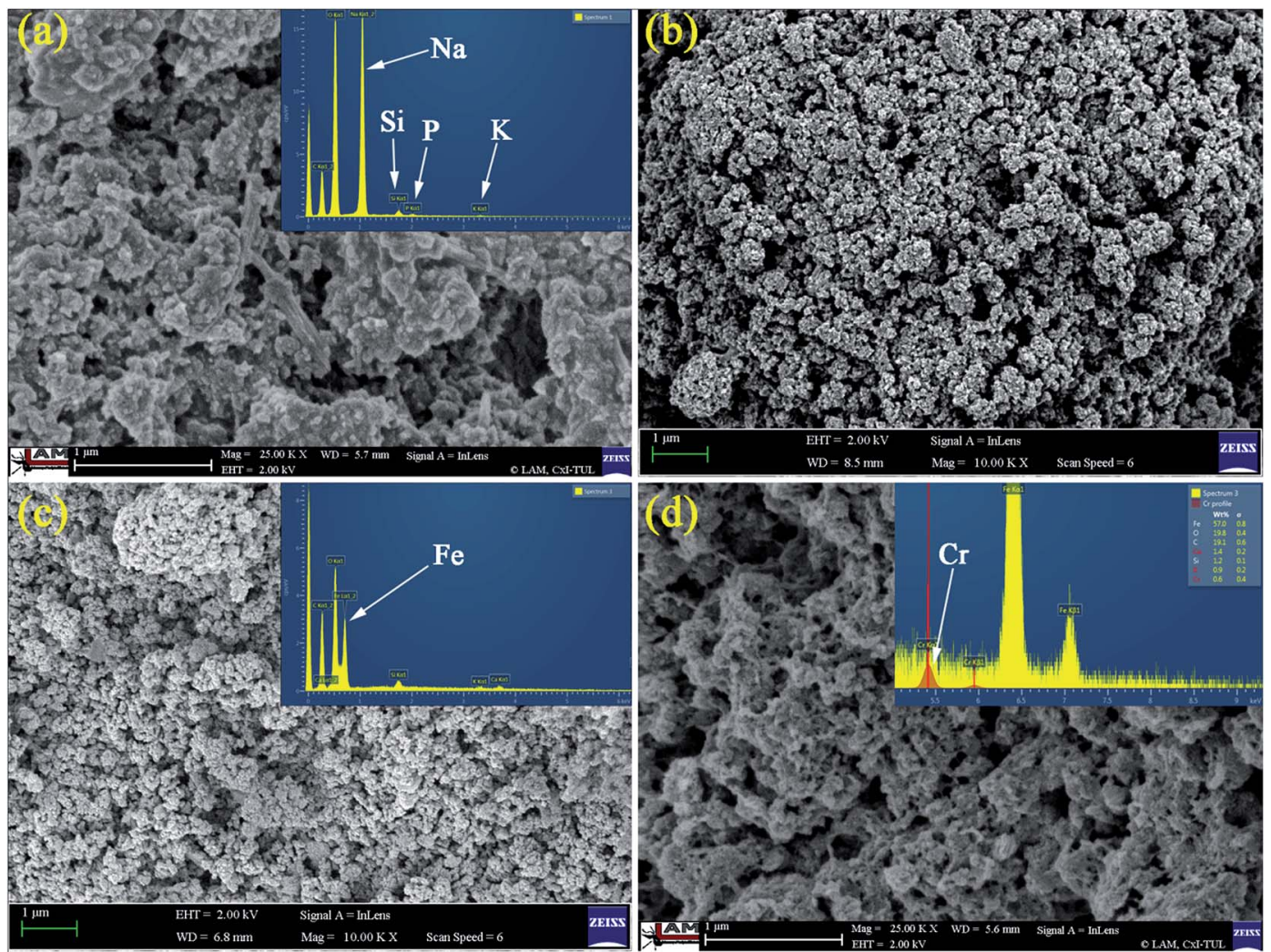

Fig. 1 SEM images of (a) lyophilized sample of GK, (b) NZVI, (c) NZVI-GK composite and (d) Cr-adsorbed NZVI-GK and their corresponding EDX profiles.

\subsection{Sedimentation experiments}

To further examine aggregation capabilities of GK, NZVI and the NZVI-GK composite, at various designated times (viz. 0, $5 \mathrm{~min}$, $30 \mathrm{~min}$, one week, one month and three months) the respective sedimentation tests were performed as presented in Fig. 4a-c. The bare NZVI particles started to settle at the bottom of the tube after $30 \mathrm{~min}$ and completely precipitated after one week (Fig. 4b). In contrast, the NZVI-GK particles remained in suspension even after three months, without any sedimentation or flocculation occurring (Fig. 4c). It was observed that NZVI-GK particles remained stable even after 3 months, as determined by particle size analysis (Fig. 3).

\subsection{Zeta potential analysis}

The surface potential charges of GK, NZVI and NZVI-GK particles were determined using zeta potential $(\zeta)$ analysis. The $\zeta$ values for GK, NZVI and NZVI-GK particles were found to be $-40 \pm 1,+0.74 \pm 0.4$ and $-23 \pm 0.5 \mathrm{mV}$ respectively at $\mathrm{pH}$ 7. The magnitude of the surface potential generally determines the level of electrostatic repulsion between particles. The NZVI particles were slightly positive at $\mathrm{pH} 7$ while GK registered a zeta potential $-40 \pm 1 \mathrm{mV}$, indicating a highly negative surface charge. Furthermore, the most important properties of GK as a stabilizing agent are as follows: nontoxicity, biodegradability, high viscosity and extensively available functional groups such as $-\mathrm{OH},-\mathrm{CO}-, \mathrm{CH}_{3} \mathrm{CO}-$ and $-\mathrm{COOH}^{.24,25}$ A low zeta potential is a useful advantage in groundwater remediation processes. In normal environmental conditions, the mobility of the NZVI particles is restricted due to the positive charge and attraction towards aquifer materials resulting in limited mobility in ground water. ${ }^{29,30}$ In combination with GK, the NZVI particle surface charges became more negative $(\zeta=-23 \pm 0.5 \mathrm{mV}$ at $\mathrm{pH}=7)$ and this could enhance the mobility of NZVI-GK in ground water. Moreover, highly negatively charged surroundings were provided by the dissociation of carboxylic acid groups present in the GK and the steric repulsion due to the latter's high molecular mass. ${ }^{25}$

\subsection{Interaction between GK and NZVI}

The major advantages of selecting gum karaya for the stabilization of NZVI are due to its properties such as biodegradability, non-toxicity, inexpensiveness and wide availability. GK provides NZVI with stability via surface charge/electrosteric stabilization. The high molecular weight of GK $\left(1.827 \times 10^{6} \mathrm{~g} \mathrm{~mol}^{-1}\right)$ induces steric hindrance arising from bulky moieties of the GK that resist interparticle interactions of the NZVI by counteracting particle-particle attractive forces leading to limited particle aggregation. In addition, GK contains multiple functional groups e.g. carbonyl (CO-), hydroxyl $(\mathrm{OH})$ and carboxylic acid $(\mathrm{COOH})$ entities, by virtue of which it functions as a stabilizer, emulsifier and thickener. Negative surface charges $(\zeta=-40 \pm$ $1 \mathrm{mV})$, molecular structures and high densities of charged 

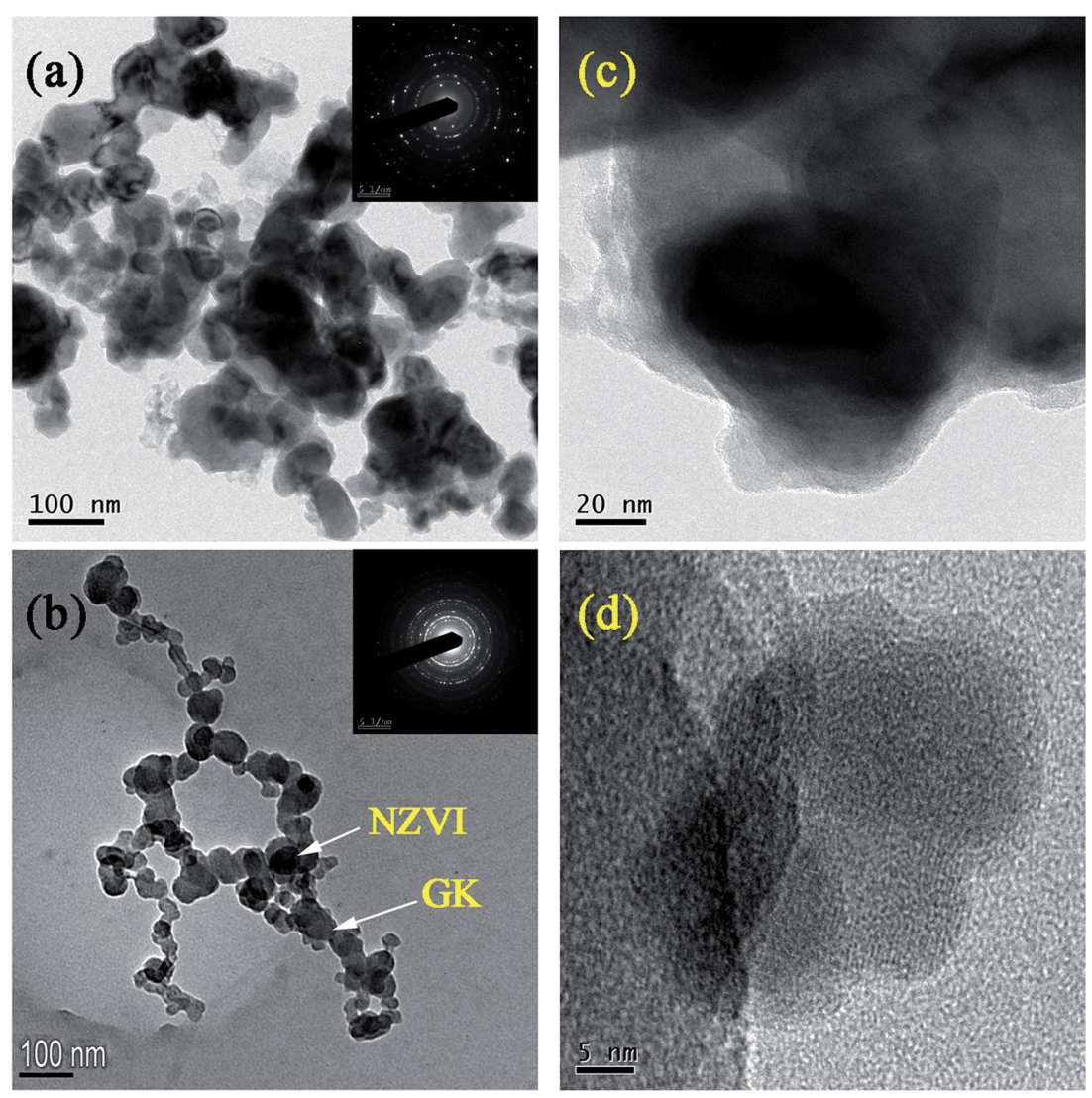

Fig. 2 TEM images of (a) bare NZVI, (b) NZVI-GK stabilized particles, and inset figures of (a) and (b) representing the selected area of diffraction patters of nanoparticles, which suggests the polycrystalline structures of NZVI. HRTEM mirographs of (c) bare NZVI and, (d) NZVI-GK stabilized nanoparticles.

functional groups all increase the likelihood of GK interacting with NZVI. The resulting stabilization enhances the dispersion of NZVI particles by adsorption of charged GK molecules to the core metal. This creates an electrical double layer and culminates in coulombic repulsion between the GK-NZVI particles. Furthermore, the elevated molecular weight and high degree of substitution of GK with varieties of functional groups (viz. OH, - $\mathrm{COO},-\mathrm{CO}$ and $-\mathrm{CH}_{3} \mathrm{CO}$ ) produce well dispersed NZVI particles with narrow size distribution ranges. Besides, GK has proved to be an effective adsorbent of toxic heavy metals and nanoparticulates due to various mechanisms such as ion-exchange, surface precipitation, chemisorption and physisorption. ${ }^{24,25,31}$

In the present study, we have demonstrated that GK bound to the surface of NZVI facilitates the formation of gel networks through hydrogen bonding and polymer entanglements, thereby preventing particle agglomeration. In addition, bidentate bridging (between GK and NZVI via the carboxylic group) resists aggregation through both electrostatic and steric repulsion (Fig. 5). Inherent properties of higher viscosity, molecular weight and the variety of functional groups present in the GK polymer all aid in stabilizing NZVI, thus arresting the particle aggregation processes. The current interpretations and overviews are compared with latest developments concerning numerous polymers such as CMC, xanthan gum, guar gum and starch, all used for the stabilization of NZVI. ${ }^{8,12,32-36}$

\section{7. $\mathrm{Cr}(\mathrm{vI})$ reduction}

Fig. 6 displays the kinetic profiles of $\mathrm{Cr}(\mathrm{vr})$ obtained when various concentrations of both NZVI and NZVI-GK were mixed with $\mathrm{Cr}(\mathrm{vI})$ solutions at an initial concentration of $10 \mathrm{mg} \mathrm{L}^{-1}$. As apparent in Fig. 6, there is a fast reduction of Cr(vI) by NZVI and NZVI-GK. After 30 minutes of reaction time, the complete removal of $\mathrm{Cr}(\mathrm{vI})$ up to $10 \mathrm{mg} \mathrm{L}^{-1}$ of the initial concentration (with the use of NZVI-GK at a dosage of $1 \mathrm{~g} \mathrm{~L}^{-1}$ ) was observed. Furthermore, it was observed that NZVI-GK exhibited greater degradation efficiency towards $\mathrm{Cr}(\mathrm{vI})$ in comparison to bare NZVI added at the same dosage. One of the possible explanations for this phenomenon could be the fact that in addition to enhancing NZVI longevity, GK can serve as an electron donor (reducing agent) for many oxidation/reduction reactions and even help stabilize metal or metal oxide nanoparticles, as reported in the literature. ${ }^{25,37,38}$ However, introduction of GK alone did not cause significant $\mathrm{Cr}(\mathrm{vI})$ reduction (data not shown). Additionally, GK's wide range of functional groups can enhance contaminant sorption more efficiently compared to bare NZVI, consequently promoting the reductive action of NZVI in juxtaposition with GK. ${ }^{39}$ However, ICP analysis confirmed that a part of the total Cr was adsorbed onto the surface of NZVI. Although GK alone has not contributed significantly to the decrease in chromium concentration in the presented timeframe, NZVI-GK 

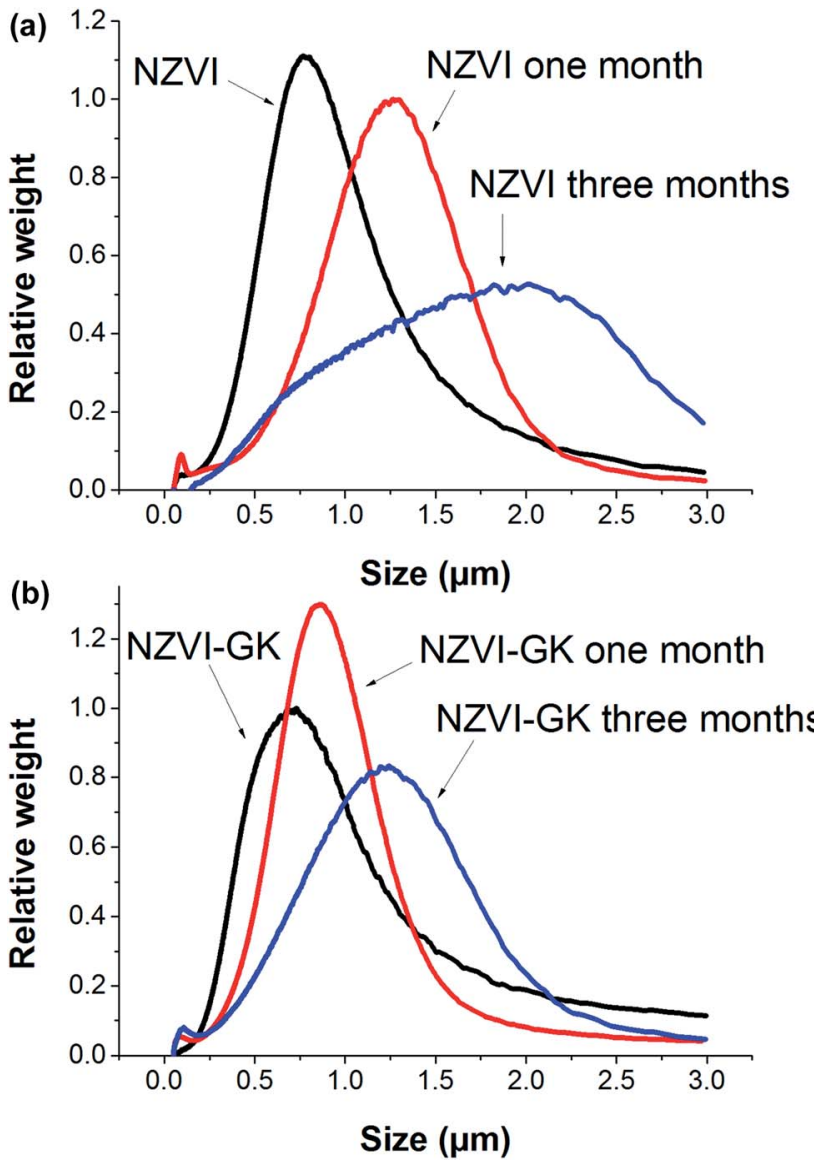

Fig. 3 Particle size distributions of (a) bare NZVI and (b) NZVI-GK particles after one week, one month and three months storage under room temperature.
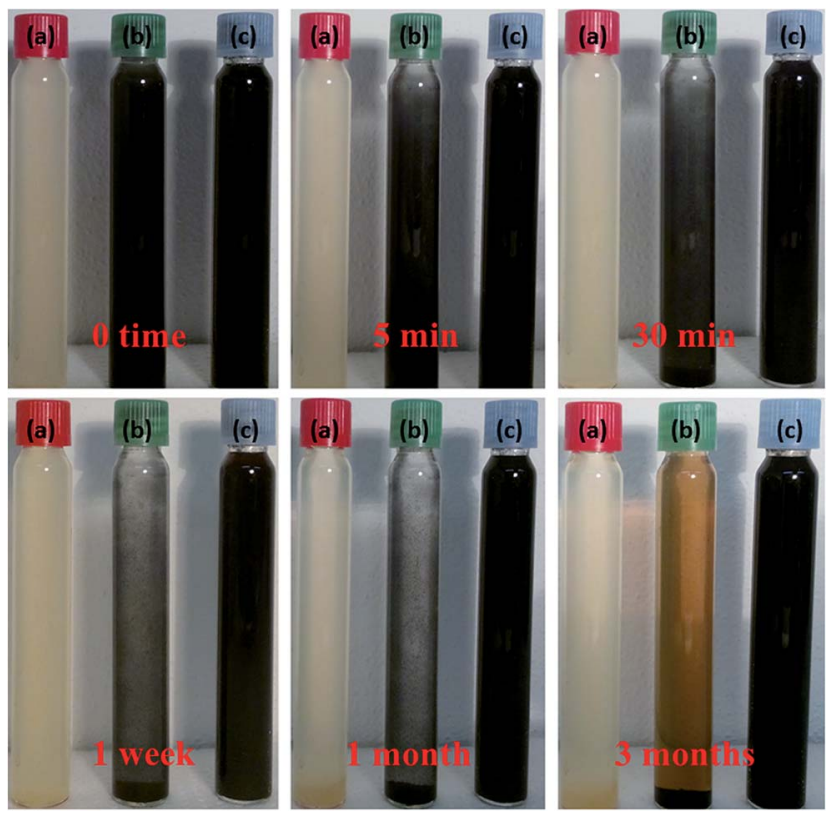

Fig. 4 Sedimentation experiments with (a) GK, (b) bare NZVI and (c) NZVI-GK particles for 0,5 min, $30 \mathrm{~min}$, one week, one month and there months storage periods under room temperatures.

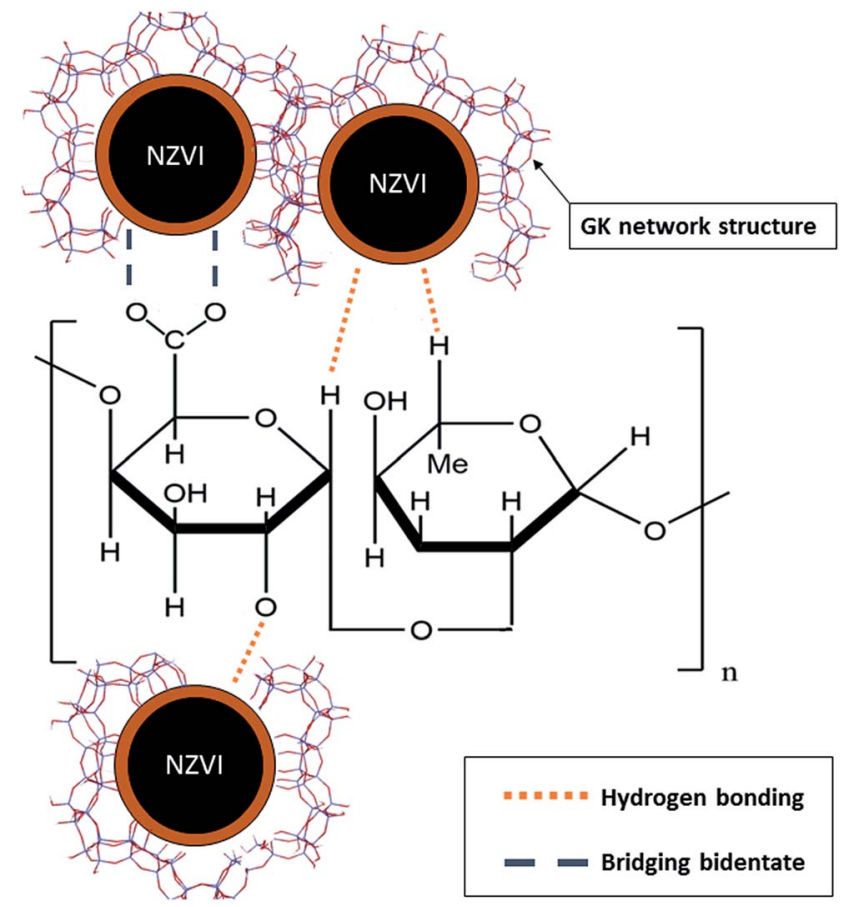

Fig. 5 The schematic presentation of NZVI interaction with GK polymer to form NZVI-GK.

has shown tremendous improvement in the removal of the total Cr [Fig. 7].

The residual total $\mathrm{Cr}$ concentration was determined to be higher than the residual $\mathrm{Cr}(\mathrm{vI})$ concentration in the experiment. This indicates that there was $\mathrm{Cr}(\mathrm{III})$ present in the solution due to the reduction of $\mathrm{Cr}(\mathrm{VI})$ to $\mathrm{Cr}(\mathrm{III})$ by interaction of $\mathrm{Cr}(\mathrm{VI})$ with NZVI-GK. The present data clearly shows that $\mathrm{Cr}(\mathrm{vI})$ was reduced to Cr(III) by NZVI-GK and that the residual $\mathrm{Cr}$ (III) in the solution was adsorbed onto the GK functional groups. This result was also confirmed by XPS analysis (Fig. 10).

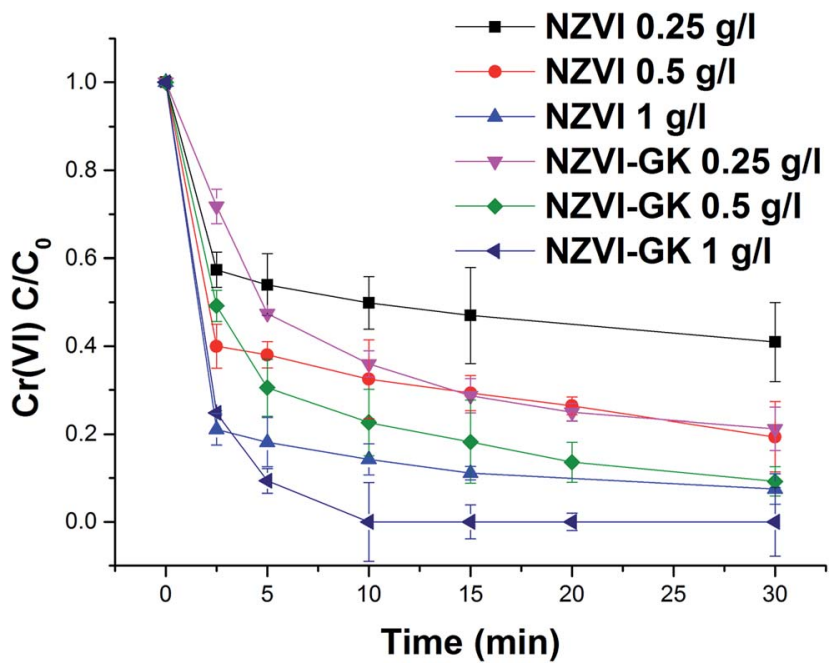

Fig. 6 Chromium(VI) decontamination with NZVI and NZVI-GK (Cr(VI) $=10 \mathrm{ppm}$, temp. $=23^{\circ} \mathrm{C}$, stirring rate $=200 \mathrm{rpm}, n=3$ ). 


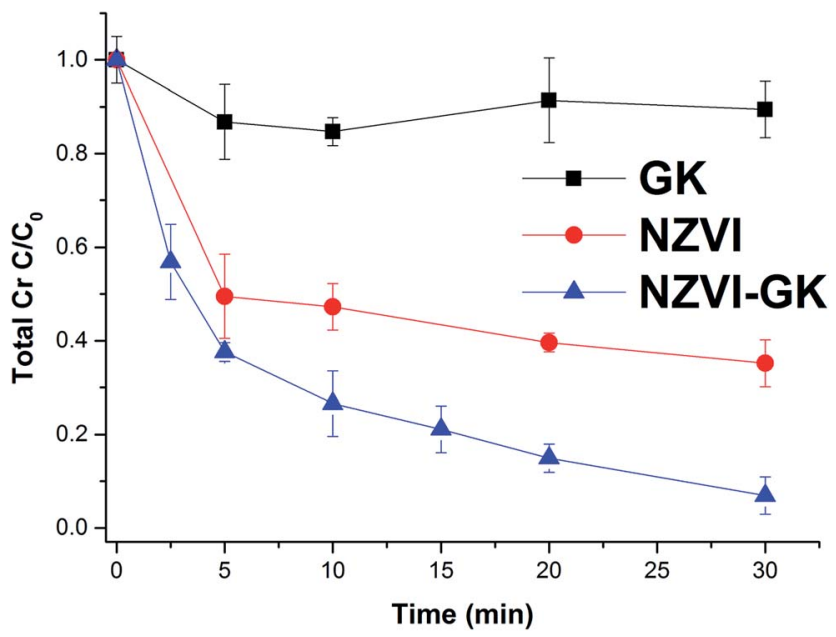

Fig. 7 Total chromium decontamination with GK, NZVI and NZVI-GK ( $\mathrm{Cr}$ conc. $=10 \mathrm{mg} \mathrm{L}^{-1}, \mathrm{GK}$ conc. $=0.5 \mathrm{~g} \mathrm{~L}^{-1}, \mathrm{NZVI}$ conc. $=1 \mathrm{~g} \mathrm{~L}^{-1}, \mathrm{NZVI}-$ GK conc. $=1 \mathrm{~g} \mathrm{~L}^{-1}$, temp. $=23^{\circ} \mathrm{C}$, stirring rate $=200 \mathrm{rpm}, n=3$ ).

Furthermore, our findings are in agreement with $\mathrm{Cr}(\mathrm{vI})$ reduction using many renewable, economical adsorbents such as gum kondagogu, Cupressus lusitanica bark, chitosan stabilized NZVI and pectin stabilized NZVI. ${ }^{37,40-43}$

\subsection{Degradation of PCE, TCE and cis-1,2-DCE}

It can be observed that stabilized and unstabilized NZVI can readily decrease the concentration of selected pollutants (Fig. 8). The reduction of chlorinated aliphatics by NZVI takes place mainly by $\beta$-elimination. ${ }^{44}$ The mechanism was established by calculating the chlorine number (please see below). Only negligible concentrations of vinylchloride (VC) were detected during the tests with NZVI. As mentioned earlier, $\beta$-elimination is the main NZVI dechlorination mechanism. However, the latter does not contribute to the formation of TCE, DCE and VC.

Furthermore, to estimate the importance of direct removal, calculation of the chlorine number was undertaken. ${ }^{45}$ The chlorine number (weighted average number of $\mathrm{Cl}$ atoms per molecule of ethene) of the groundwater ranged from 3.1 to 4 during the experimental period (ESI Fig. S1†). The chlorine number remained almost constant without showing any decrease which proves that (i) simultaneous degradation of all chlorinated hydrocarbons has occurred and (ii) no lower chlorinated hydrocarbons had been formed. The fluctuations of the chlorine number are attributable to a low measured concentration of some ethenes (close to the detection limit).

The sum of chlorinated hydrocarbon concentrations (in the blank test) was observed not to have decreased more than $15 \%$. According to the literature from many sources the major product of reductive dechlorination is ethene (an alkene that was not measured in this study). ${ }^{46}$ Moreover, chlorine number calculations (as described earlier) have confirmed the complete dechlorination of contaminants without significant formation of less chlorinated hydrocarbons. This can be elucidated by the fact that NZVI serves as an efficacious electron donor from the iron surface to the hydrocarbon for reductive dehalogenation of VOCs. Similar to work presented by Fu et al. ${ }^{47}$ the degradation ability of VOCs by surface modified NZVI can significantly increase in comparison to conventional NZVI. Moreover, large differences in degradation efficacy towards chlorinated

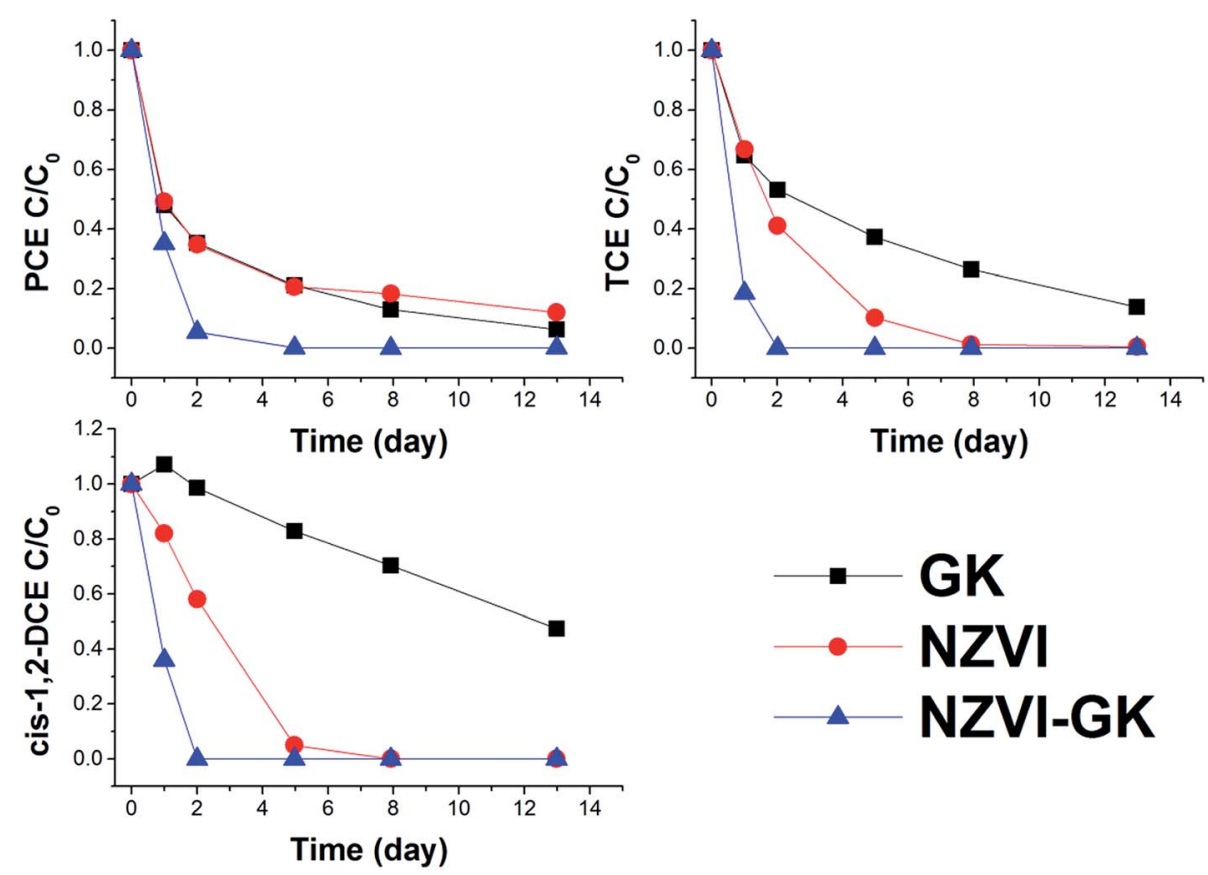

Fig. 8 Removal of VOCs (perchloroethene (PCE), trichloroethene (TCE) and cis-1,2-DCE (cis-1,2-dichloroethene)) from effluent at the Pisecna site with GK, NZVI and NZVI-GK (temp. $=23^{\circ} \mathrm{C}, \mathrm{GK}$ conc. $=0.5 \mathrm{~g} \mathrm{~L}^{-1}, \mathrm{NZVI}$ conc. $=5 \mathrm{~g} \mathrm{~L}^{-1}, \mathrm{NZVI}-\mathrm{GK}$ conc. $=5 \mathrm{~g} \mathrm{~L}^{-1}$ ). 
hydrocarbons (as well as chromium) suggest that stabilization with GK can enhance not only the NZVI surface reactivity per unit area but also increase the sorption area of the resultant nanoparticles.

\subsection{NZVI-biopolymer stabilization and degradation of environmental pollutants}

Table 1 summarizes comparative results of different biopolymers used for the stabilization of NZVI and their efficiencies towards the degradation of the pollutants. ${ }^{16,35,43,48-60}$ Extensive studies have demonstrated that both polymers and surfactants are effective in inhibiting NZVI aggregation and enhancing mobility in the subsurface for emplacement. The major factors which influence stabilization of NZVI, namely surface modification, emulsification and conjugation with polymer, have also proved able to provide protection to NZVI against aggregation and surface oxidation, in addition to promoting transport in subsurface environments. The stabilization methods not merely increase the mobility but also the reactivity of NZVI towards hazardous/toxic environmental contaminants. It is difficult to categorically state that a particular biopolymer is the best one, both to stabilize the NZVI and to enhance its ability to speedily degrade environmental pollutants. However, with regard to the biodegradability, non-toxicity and economic viability of these natural products (coupled with their physicochemical characteristics that confer stability to NZVIs) there is no doubt that the sustainability of natural polymer stabilized NZVIs would be highly sought after, in the field of environmental remediation. It has been observed that polymer stabilized NZVIs have a higher degradation efficiency, compared to nonstabilized NZVIs, towards the various pollutants (Table 1) tested. For example, $\mathrm{Cr}(\mathrm{vI})$ removal efficiency of CMC-stabilized NZVI is approximately four times higher than non-stabilized NZVI. ${ }^{51}$ Similarly, trichloroethylene degradation efficiency of CMC-stabilized bimetallic NZVI/Pd was reported to be 17 times higher than its non-stabilized counterparts, in terms of TCE degradation rate constants. ${ }^{57}$ The use of MZVI (microsized zerovalent nanoparticles) rather than NZVI has been reported. ${ }^{\mathbf{4 8 , 4 9}}$ The major benefits of using MZVI rather than NZVI are the lower costs ( $1 / 20$ to $1 / 3$ for MZVI compared to NZVI), lower corrosion rates (10 to 30 times lower than NZVI) and easier handling of microsized particles compared to nanosized ones. ${ }^{59}$

\subsection{XRD analysis}

XRD patterns of GK, NZVI, NZVI-GK, and Cr/NZVI-GK are presented in Fig. 9. GK is amorphous in nature and there were no peaks observed in its XRD pattern (Fig. 9). The presence of NZVI-GK was confirmed by strong peaks at $2 \theta=44.7^{\circ}$ corresponding to the (110) plane of $\mathrm{Fe}^{0}$ nanoparticles, suggesting that GK stabilized NZVI via air oxidation (Fig. 9). Similar

Table 1 A comparative study of various natural polymers used for the stabilization of NZVI and its application for the degradation of environmental pollutants

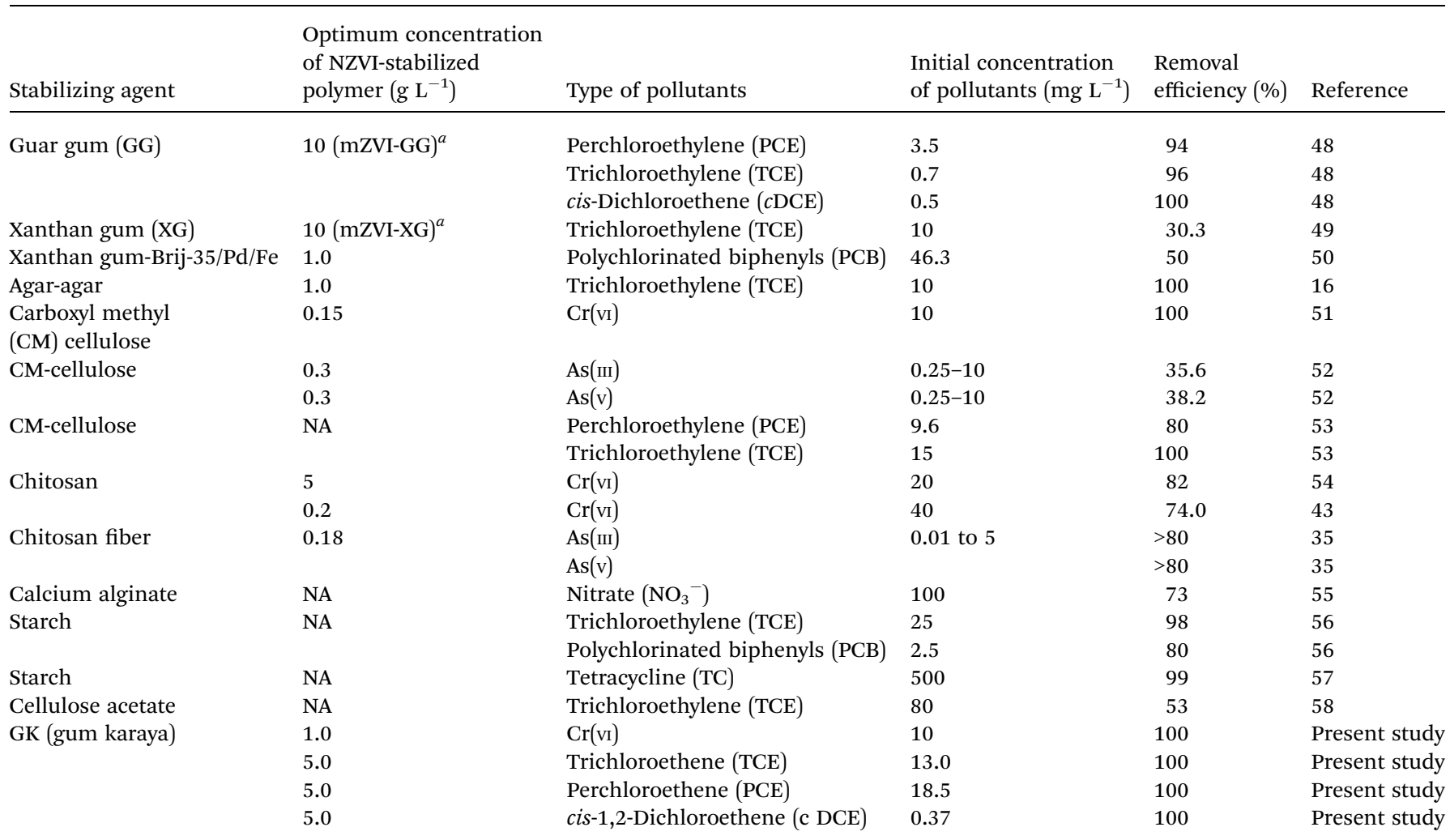

${ }^{a} \mathrm{mZVI}=$ micro size zerovalent iron particles, NA - not analysed. 


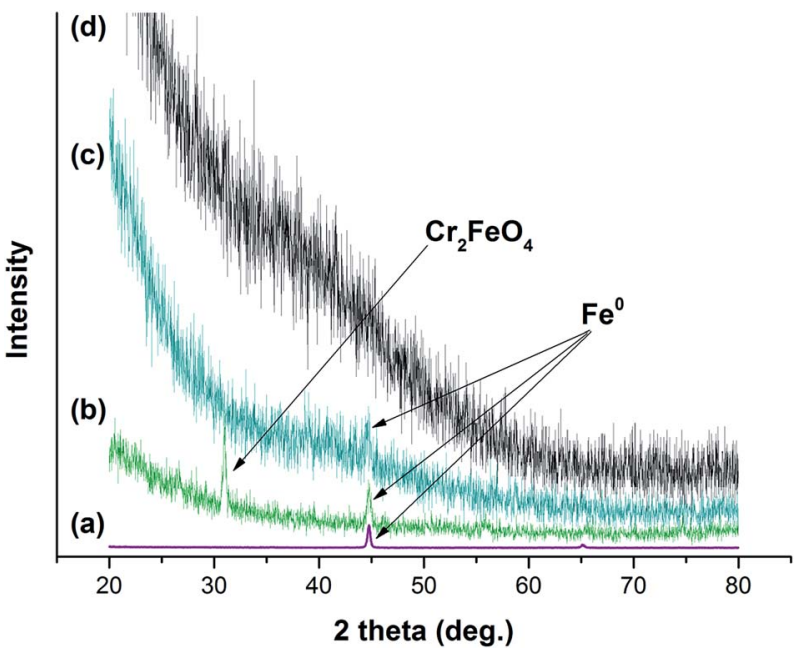

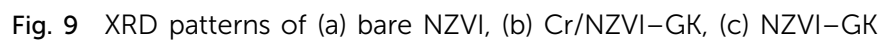
and (d) GK.

observations were reported for chitosan stabilized NZVI. ${ }^{\mathbf{4 1}}$ The XRD patterns of the $\mathrm{Cr} / \mathrm{NZVI-GK}$ composite showed peaks at $\gamma$ $\mathrm{Fe}_{2} \mathrm{O}_{3}\left(2 \theta=36^{\circ}\right), \mathrm{Fe}_{3} \mathrm{O}_{4}\left(2 \theta=36 / 57 / 62.5^{\circ}\right)$ and $\mathrm{Cr}_{2} \mathrm{FeO}_{4}(2 \theta=$ $35.50^{\circ}$ ) after $\mathrm{Cr}$ interaction with NZVI-GK, suggesting the possible occurrence of redox reactions between NZVI and $\operatorname{Cr}(\mathrm{vI})$. These results were supported by XPS analysis where $\operatorname{Cr}(\mathrm{vI})$ is reduced to $\mathrm{Cr}(\mathrm{III})$ during the interaction between $\mathrm{Cr}(\mathrm{VI})$ with NZVI-GK in which the NZVI particles acted as the reductant. Similar findings were reported for NZVI supported multi-walled carbon nanotubes for the removal of $\mathrm{Cr}(\mathrm{vI})$ from waste water. ${ }^{\mathbf{6 0}}$

\subsection{X-ray photoelectron analysis}

The XPS technique is a useful tool for characterizing the ligand effect in transition metal complexes and electron-donating ligands will lower the binding energy (BE) of the core-level electrons while electron-withdrawing ligands will do the reverse. The technique is also employed to identify the existence of a particular element in a material and to distinguish the different oxidation states of the same element. ${ }^{61}$ The XPS survey scan (Fig. 10) shows the binding energy peaks of carbon and oxygen in GK and in the case of NZVI-GK, the Fe 2p spectrum for $\mathrm{Fe}(0)$. The $2 \mathrm{p}_{3 / 2}$ peak is centred at a binding energy of $710.2 \mathrm{eV}$ while the $2 \mathrm{p}_{1 / 2}$ peak has a $\mathrm{BE}$ of $732.8 \mathrm{eV}$, representing $\gamma-\mathrm{Fe}_{2} \mathrm{O}_{3} \cdot{ }^{62-65}$ The satellite peak at $706.69 \mathrm{eV}$ suggests that $\mathrm{Fe}(0)$ is present on the surface of the NZVI-GK composite. ${ }^{63,65}$ The XPS spectra for GK, before and after metal adsorption of total chromium, are shown in Fig. 10. As can be seen from the spectra, the XPS survey scans for GK show binding energy peaks characteristic of carbon and oxygen. The spectrum of the metal adsorbed onto GK indicates the presence of chromium (Fig. 10c) on the surface of the polymer, obviously after metal biosorption. This is in addition to carbon and oxygen. Highresolution narrow scans of $\mathrm{C}$ 1s core-level spectra of GK samples before and after metal adsorption comprise three peaks corresponding to binding energies of 284.59, 286.36 and $288.29 \mathrm{eV}$ - assigned to $\mathrm{C}-\mathrm{H}, \mathrm{C}-\mathrm{O}$ and $\mathrm{C}=\mathrm{O}$ that were identified
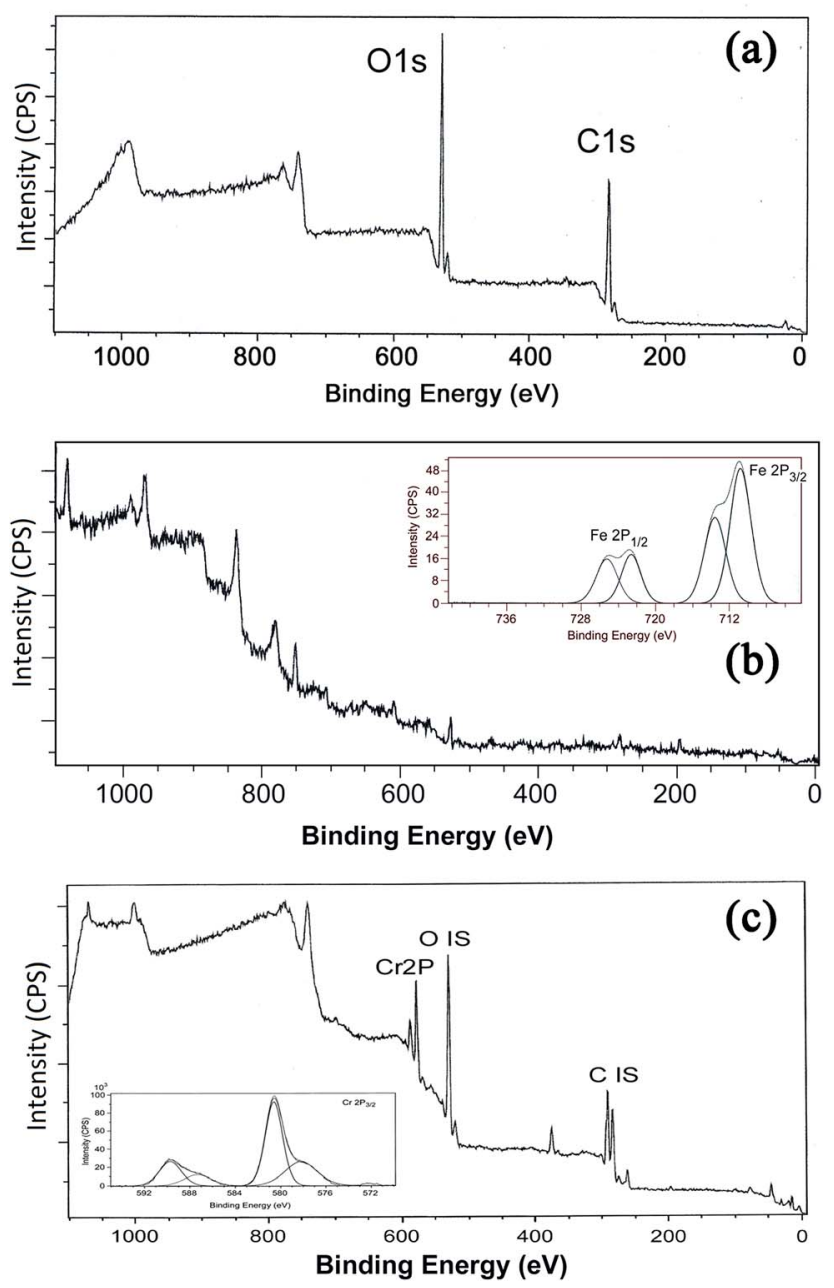

Fig. $10 \mathrm{X}$-ray photoelectron spectroscopy of (a) GK - full survey showing the major oxygen (1s) and carbon (1s) peaks, (b) NZVI-GK composite and (c) $\mathrm{Cr} / \mathrm{NZVI-GK}$.

via the deconvolution. ${ }^{66,67}$ The observed $\mathrm{C}$ 1s binding energy peaks were assigned to the $\mathrm{C}-\mathrm{C}, \mathrm{C}-\mathrm{O}$ and $\mathrm{C}=\mathrm{O}$ functional groups present in GK. This is in agreement with the observations made by ATR-FTIR (Fig. 11). The peaks for $\mathrm{C}-\mathrm{O}$ and $\mathrm{C}=\mathrm{O}$ can be assigned to hydroxyl and carboxylate groups present in GK. The $\mathrm{O}$ 1s high-resolution narrow scans could be deconvoluted into binding energy peaks at 531.8 and $532.7 \mathrm{eV}$ which can be ascribed correspondingly to the $\mathrm{O}$ in the $\mathrm{C}=\mathrm{O}$ and alcoholic $\mathrm{C}-\mathrm{O}$ groups. The $\mathrm{C}=\mathrm{O}$ group may be present due to the carboxylate groups inherent in GK. Chromium adsorbed onto GK was also analyzed by XPS to confirm the presence of $\mathrm{Cr}$ and its oxidation states.

Low-resolution XPS spectra of the Cr-free GK indicated that apart from $\mathrm{C}$ and $\mathrm{O}$, there were no significant contributions from other elements associated with the GK structure. Highresolution spectra of the Cr-loaded NZVI-GK revealed that there were significant inputs from the $\mathrm{Cr}$ bound onto the NZVI-GK (Fig. 10c). Significant bands appeared at binding energies of 578 and $587 \mathrm{eV}$, the former corresponding to the $\mathrm{Cr}$ $2 \mathrm{p}_{3 / 2}$ orbital, the latter to the $2 \mathrm{p}_{1 / 2}$ orbital. The deconvoluted 


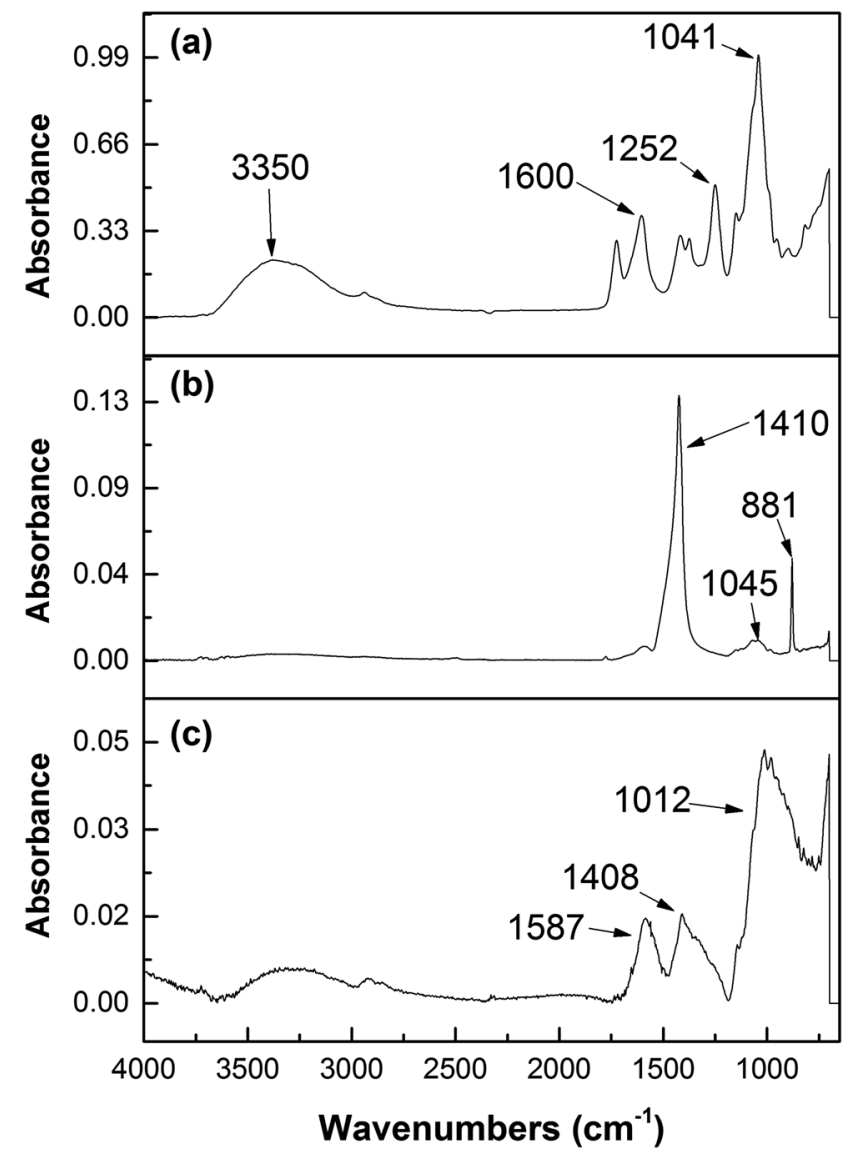

Fig. 11 ATR-FTIR characterization of (a) GK, (b) NZVI-GK and (c) $\mathrm{Cr}$ / $\mathrm{NZVI-GK}$

binding energy peaks for $\mathrm{Cr} 2 \mathrm{p}_{3 / 2}$ at $578.2 \mathrm{eV}$ and $\mathrm{Cr} 2 \mathrm{p}_{1 / 2}$ at $587.4 \mathrm{eV}$ were assigned to $\mathrm{Cr}_{2} \mathrm{O}_{3}$ for $\mathrm{Cr}^{3+}$ compounds while $\mathrm{Cr}^{6+}$ displayed characteristic peaks at higher binding energies (viz. 580.6 and $589.7 \mathrm{eV}$ ) ascribed to $\mathrm{Cr} 2 \mathrm{p}_{3 / 2}$ at $578.2 \mathrm{eV}$ and $\mathrm{Cr} 2 \mathrm{p}_{1 / 2}$, respectively. ${ }^{68-70}$ Thus, the spectra for $\mathrm{Cr}$ adsorbed onto NZVI-GK implied the existence of $\mathrm{Cr}^{3+}$ on the surface of NZVI-GK. The presence of $\mathrm{Cr}^{6+}$ on the GK structure is also feasible, although no sorption of $\mathrm{Cr}^{6+}$ onto GK was observed during the degradation tests. It was previously reported that $\mathrm{Cr}^{6+}$ could be bound to an oat by-product which was easily reduced to $\mathrm{Cr}^{3+}$ by positively charged functional groups and subsequently adsorbed by the available carboxyl groups. ${ }^{71}$ Sheng et al. ${ }^{72}$ found that $\mathrm{Cr}^{6+}$ was completely reduced to $\mathrm{Cr}^{3+}$ by contact with the biomass of the brown seaweed Ecklonia below pH 5. XPS spectra of Cr-bound GK revealed that most of the Cr-bound on the surface of GK was in the $\mathrm{Cr}^{3+}$ state. This was confirmed by ICP analysis. Murphy et al. ${ }^{73}$ showed that $\mathrm{Cr}$ binding altered the relative quantities of carbonyl and alcohol groups in seaweed biomass polysaccharides, thus underscoring the importance of these functional groups in binding and reduction of $\mathrm{Cr}^{6+}$ to $\mathrm{Cr}^{3+}$. The XPS methods demonstrate that metal ion interactions with GK in several forms involve various changes in the metal oxidation state, as well as in the chemical state of the reactive sites of GK.

\subsection{ATR-FTIR analysis}

To identify the functional groups that participate in NZVI-GK chemistry, FTIR characterization was carried out. High intensity peaks in the region of $1040 \mathrm{~cm}^{-1}$ could be ascribed to the binding of NZVI particles onto the surface of the GK matrix (Fig. 11b).

The intensity of O-H stretching at $3359 \mathrm{~cm}^{-1}$ for the NZVIGK composite (Fig. 11b) was lower than that for the native structure of GK (Fig. 11a). The peaks at $1721 \mathrm{~cm}^{-1}$ and 1252 $\mathrm{cm}^{-1}\left(\mathrm{CH}_{3} \mathrm{CO}\right.$ group) present in the GK spectra shown (in Fig. 11a) were also displayed by NZVI-GK (Fig. 11b) suggesting that the acetyl groups played an important role in the formation of the NZVI-GK composite. Another peak shift (from $1408 \mathrm{~cm}^{-1}$ to $1370 \mathrm{~cm}^{-1}$ ) was observed in the case of NZVI-GK, implying that both the carbonyl and hydroxyl functional groups of GK had a strong affinity to bind onto the NZVI nanoparticles. The lower peak at $1600 \mathrm{~cm}^{-1}$ in NZVI-GK (compared to the peak for GK) indicated that the negatively charged $\mathrm{COO}^{-}$groups bound to positive sites on the surface of the NZVI. FTIR spectra for CrNZVI-GK (Fig. 11c) revealed perceptible changes (compared to that shown by NZVI-GK) implying that Cr adsorption had taken place. The spectra comprised two new peaks at 774 and 904 $\mathrm{cm}^{-1}$, attributed respectively to the $\mathrm{Cr}-\mathrm{O}$ and $\mathrm{Cr}=\mathrm{O}$ bonds (from the $\mathrm{Cr}$ species) suggesting that $\mathrm{Cr}$ was adsorbed onto the surface of NZVI-GK, as has previously been reported for $\mathrm{Cr}$ adsorption onto chitosan/Fe(II)/PVA nanofibers and crosslinked xanthated chitosan. ${ }^{74,75}$

\subsection{Thermal analysis}

Fig. 12 displays the thermal decomposition profiles of the GK and NZVI-GK particles, respectively. After heating beyond $250{ }^{\circ} \mathrm{C}$, weight loss occurred sharply and GK appeared to have decomposed completely when the temperature exceeded $700^{\circ} \mathrm{C}$ (Fig. 12). On the other hand, over the same temperature range, the NZVI-GK particles yielded more than $60 \%$ of the initial weight. The remaining residue of the NZVI-GK can be attributed mainly to the iron based species developed on the GK scaffold. The thermal decomposition behaviour of GK is in close

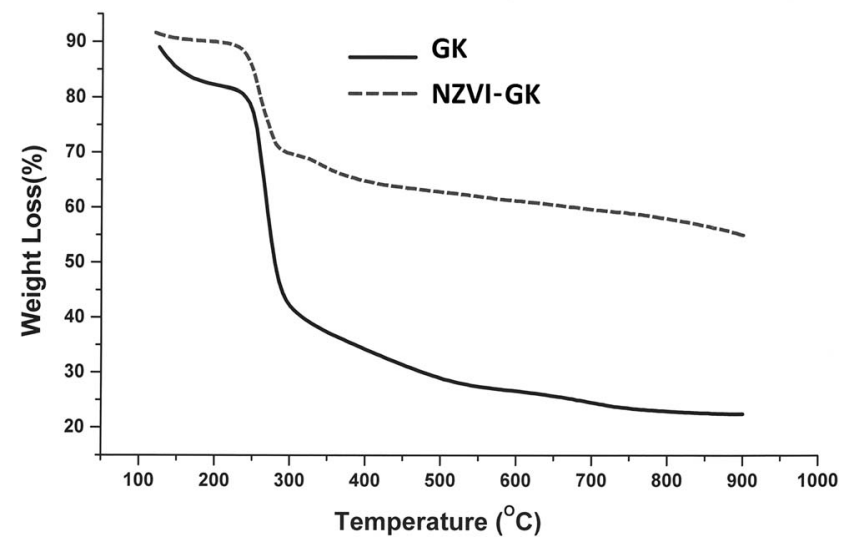

Fig. 12 TGA curves of GK and NZVI-GK, indicating thermal decomposition from $100-800^{\circ} \mathrm{C}$ under nitrogen atmosphere. 
agreement with that exhibited by gum arabic - a natural biopolymer, very similar to the GK. ${ }^{76}$ In the case of GK-NZVI, a weight loss of $\sim 35 \%$ was observed at $\sim 300{ }^{\circ} \mathrm{C}$, due to the decomposition of GK but no further weight loss occurred. By means of TG analysis, approximately $65 \%$ of the NZVI particles were estimated to be located in the NZVI-GK composite. This result was corroborated by thermal analysis data of chitosan stabilized NZVI in the literature. ${ }^{41}$

\section{Conclusions}

In this study it was demonstrated that using $10 \mathrm{~g} \mathrm{~L}^{-1}$ of GK, a "green" tree polysaccharide could stabilize NZVI particles at a concentration of $200 \mathrm{~g} \mathrm{~L}^{-1}$ in the mixture (comprising a $1: 1$ GK : NZVI ratio) over a duration of three months. No aggregation or sedimentation of stabilized NZVI particles was observed. The improved reactivity of the NZVI-GK composite towards $\mathrm{Cr}$ reduction and degradation of VOCs was found to be superb in comparison to the bare NZVI particles. Furthermore, XPS and ICP-MS results revealed that $\mathrm{Cr}(\mathrm{VI})$ was reduced to $\mathrm{Cr}$ (III) by NZVI-GK and the Cr(III) remaining in solution was adsorbed onto the GK polymer. Thus the total removal of chromium from the contaminated water was achieved. The work presents GK as an inexpensive and environmentally friendly material for NZVI stabilization that can adequately serve large scale remediation of contaminated water and soil.

\section{Conflict of interests}

The authors declare no conflict of interests.

\section{Acknowledgements}

The research reported in this paper was financially supported by the Ministry of Education, Youth and Sports in the framework of the targeted support of the "National Programme for Sustainability I" (LO 1201) and the OPR\&DI project "Extension of CxI facilities" (CZ.1.05/2.1.00/19.0386). The authors also acknowledge the assistance provided by the Research Infrastructure NanoEnviCz, supported by the Ministry of Education, Youth and Sports of the Czech Republic under Project No. LM2015073.

\section{Notes and references}

1 D. O'Carroll, B. Sleep, M. Krol, H. Boparai and C. Kocur, Adv. Water Resour., 2013, 51, 104.

2 R. A. Crane and T. B. Scott, J. Hazard. Mater., 2012, 211-212, 112.

3 T. Tosco, M. P. Papini, C. C. Viggi and R. Sethi, J. Cleaner Prod., 2014, 77, 10.

4 T. Tosco, M. Coisson, D. Xue and R. Sethi, in Nanoparticles Featuring Electromagnetic properties: From Science To Engineering, ed. A. Chioerio and P. Allia, Research Signpost, Kerala, 2012, pp. 201-223.

5 F. He and D. Y. Zhao, Environ. Sci. Technol., 2005, 39, 3314.
6 N. Saleh, T. Phenrat, K. Sirk, B. Dufour, J. Ok, T. Sarbu, K. Matyjaszewski, R. D. Tiilton and G. V. Lowry, Nano Lett., 2005, 5, 2489.

7 N. D. Berge and C. A. Ramsburg, Environ. Sci. Technol., 2009, 43, 5060 .

8 A. Tiraferri, K. L. Chen, R. Sethi and M. Elimelech, J. Colloid Interface Sci., 2008, 324, 71.

9 E. Dalla Vecchia, M. Luna and R. Sethi, Environ. Sci. Technol., 2009, 43, 8942.

10 H. Dong and I. M. C. Lo, Water Res., 2013, 47, 419.

11 M. M. Krol, A. J. Oleniuk, C. M. Kocur, B. E. Sleep, P. Bennett, Z. Xiong and D. M. O'Carroll, Environ. Sci. Technol., 2013, 47, 7332.

12 S. Comba, D. Dalmazzo, E. Santagata and R. Sethi, J. Hazard. Mater., 2011, 185, 598.

13 D. Xue and R. Sethi, J. Nanopart. Res., 2012, 14, 1239.

14 T. L. Kirschling, P. L. Golas, J. M. Unrine, K. Matyjaszewski, K. B. Gregory, G. V. Lowry and R. D. Tilton, Environ. Sci. Technol., 2011, 45, 5253.

15 F. Gastone, T. Tosco and R. Sethi, J. Colloid Interface Sci., 2014, 421, 33.

16 M. Velimirovic, D. Schmid, S. Wagner, V. Micic, F. von der Kammer and T. Hofmann, Sci. Total Environ., 2015, 563564, 713.

17 S. Comba and R. Sethi, Water Res., 2009, 43, 3717.

18 D. W. Elliott and W. X. Zhang, Environ. Sci. Technol., 2001, 35, 4922.

19 D. Verbeken, S. Dierchx and K. Dewettinck, Appl. Microbiol. Biotechnol., 2003, 63, 10-21.

20 V. T. P. Vinod, C. Senan and M. Černík, Dodecenyl succinic anhydride derivatives of gum karaya (Sterculia urens), J. Agric. Food Chem., 2015, 63, 3757.

21 D. M. W. Anderson, C. G. A. McNab, C. G. Anderson, P. M. Braown and M. A. Pringuer, International Tree Crops Journal, 1982, 2, 147.

22 D. Le Cerf, F. Irinei and G. Muller, Carbohydr. Polym., 1990, 13, 375 .

23 A. C. F. Brito, M. R. Sierakowski, F. Reicher, J. P. A. Feitosa and R. C. M. de Paula, Food Hydrocolloids, 2005, 19, 861.

24 V. T. P. Vinod and M. Černík, Int. J. Nanomed., 2013, 8, 889. 25 V. T. P. Vinod, R. B. Sashidhar, N. Sivaprasad, U. V. M. Sarma, N. Satyanarayana, R. Kumaresan, T. Nagaeswara Rao and P. Raviprasad, Desalination, 2011, 272, 270.

26 S. Wacławek, J. Nosek, L. Cádrová, V. Antoš and M. Černík, Ecol. Chem. Eng. S, 2015, $22,4$.

$27 \mathrm{HACH}, \mathrm{DR} / 2400$ Method 8023, Chromium, hexavalent(1,5diphenyl carbohydrazide method), Laboratory manual, Standard Methods for the Examination of Water and Wastewater, Loveland, CO, 5th edn, 2008.

28 D. J. Fyfe, Rapid, automated and cost-effective analyses of hexavalent chromium for WEEE/RoHS using the Varian Cary 50 UV-Vis Microplate Reader System, Varian Inc, 2014, application note 00533 .

29 Y. P. Sun, X.-Q. Li, W.-X. Zhang and H. P. Wang, Colloids Surf., A, 2007, 308, 60-66. 
30 W. Stumm and J. J. Morgan, Aquatic chemistry, John Wiley \& Sons, New York, 3rd edn, 1996.

31 V. V. T. Padil and M. Černík, J. Hazard. Mater., 2016, 287, 102. 32 X. Zhao, W. Liu, Z. Cai, B. Han, T. Qian and D. Zhao, Water Res., 2016, 100, 245.

33 T. Phenrat, N. Saleh, K. Sirk, H. J. Kim, R. D. Tilton and G. V. Lowry, J. Nanopart. Res., 2008, 10, 795.

34 R. Singh and V. Misra, Handbook of nanoparticles, Springer Int. Publishing, Switzerland, 2015.

35 N. Sakulchaicharoen, D. M. O'Carroll and J. E. Herrera, J. Contam. Hydrol., 2010, 118, 117.

36 A. Tiraferri and R. Sethi, J. Nanopart. Res., 2009, 11, 635.

37 V. T. P. Vinod, R. B. Sashidhar and B. Sreedhar, J. Hazard. Mater., 2010, 178, 851.

38 V. V. T. Padil, S. Wacławek and M. Cernik, Ecol. Chem. Eng. S, 2016, 23, 533.

39 V. V. T. Padil, N. H. A. Nguyen, A. Sevcu and M. Cernik, J. Nanomater., 2015, 750726, DOI: 10.1155/2015/750726.

40 A. R. Netzahuati-Munoz, Md. C. Cristiani-Urbina and E. Cristiani-Urbina, PLoS One, 2015, 10, e0137086.

41 N. Horzum, M. M. Demir, M. Nairat and T. Shahwan, $R S C$ Adv., 2013, 3, 7828.

42 D. Chen, K. Yang, H. Wang, J. Zhou and H. Zhang, RSC Adv., 2015, 5, 65068.

43 B. Geng, Z. Jin, T. Li and X. Qi, Sci. Total Environ., 2009, 407, 4994.

44 M. Tobiszewski and J. Namieśnik, Environ. Sci. Pollut. Res. Int., 2012, 19, 1994.

45 J. Němeček, P. Pokorný, O. Lhotský, V. Knytl, P. Najmanová, J. Steinová, M. Černík, A. Filipová, J. Filip and T. Cajthaml, Sci. Total Environ., 2016, 563, 822.

46 L. Di Palma, P. De Filippis, D. Lausdei and E. Petrucci, Environ. Eng. Manage. J., 2015, 14, 2713.

47 F. Fu, D. D. Dionysiou and H. Liu, J. Hazard. Mater., 2014, 267, 194.

48 M. Luna, F. Gastone, T. Tosco, R. Sethi, M. Velimirovic, J. Gemoets, R. Muyshond, H. Sapion, N. Klaas and L. Bastiaens, J. Contam. Hydrol., 2015, 181, 46.

49 J. Xin, J. Han, X. Zheng, H. Shao and O. Kolditz, J. Environ. Manage., 2015, 150, 420.

50 G. Fan, L. Cang, W. Qin, C. Zhou, H. I. Gomes and D. Zhou, Sep. Purif. Technol., 2013, 114, 64.

51 Q. Wang, H. Qian, Y. Yang, Z. Zhang, C. Naman and X. Xu, J. Contam. Hydrol., 2010, 114, 35.

52 M. Mosaferi, S. Nemati, A. Khataee, S. Nasseri and A. A. Hashemi, J. Environ. Health Sci. Eng., 2014, 12, 74.

53 F. He, D. Zhao and C. Paul, Water Res., 2010, 44, 2360.
54 T. Liu, L. Zhao, D. Sun and X. Tan, J. Hazard. Mater., 2010, 184, 724.

55 A. N. Bezbaruah, S. Krajangpan, B. J. Chisholm, E. Khan and J. J. Elorza Bermudez, J. Hazard. Mater., 2009, 166, 1339.

56 F. He and D. Zhao, Environ. Sci. Technol., 2005, 39, 3314.

57 Y. Fu, L. Peng, Q. Zeng, Y. Yang, H. Song, J. Shao, S. Liu and J. Gu, Chem. Eng. J., 2015, 270, 631.

58 L. Wu, M. Shamsuzzoha and S. M. C. Ritchie, J. Nanopart. Res., 2005, 7, 469.

59 M. Velimirovic, L. Carniato, Q. Simons, G. Schoups, P. Seuntjens and L. Bastiaens, J. Hazard. Mater., 2014, 270, 18.

60 X. Lv, J. Xu, G. Ji and X. Xu, Chemosphere, 2011, 85, 1204.

61 L. Dambies, C. Guimon, S. Yiacoumis and E. Guibal, Colloids Surf., A, 2001, 177, 203.

62 R. M. Cornell and U. Schwertmann, The Iron Oxides: Structure, Properties, Reactions, Occurrences and Uses, WileyVCH. Weinheim, 2nd edn, 2003.

63 G. S. Allen, M. T. Curtis, A. J. Hooper and P. M. Tucker, Dalton Trans., 1974, 14, 1525.

64 K. Asami and K. Hashimoto, Corros. Sci., 1977, 17, 559.

65 J. T. Nurmi, P. G. Tratnyek, V. Sarathy, D. R. Baer, J. E. Amonette, K. Pecher, C. Wang, J. C. Linehan, D. W. Matson, R. Lee Penn and M. D. Driessen, Environ. Sci. Technol., 2005, 39, 1221.

66 L. H. Dubois, B. R. Zegarski and R. G. Nuzzo, Langmuir, 1986, $2,412$.

67 M. Wuhn, J. Weckesser and C. Woll, Langmuir, 2001, 17, 7605.

68 E. Frydman, H. Cohen, R. Maoz and J. Sagiv, Langmuir, 1997, 13, 5089.

69 X. Q. Li, J. Cao and W. X. Zhang, Ind. Eng. Chem. Res., 2008, 47, 2131.

70 B. A. Manning, J. R. Kiser, H. Kwon and S. R. Kanel, Environ. Sci. Technol., 2007, 41, 586.

71 J. L. Gardea-Torresdey, K. J. Tiemann, V. Armendariz, L. Bess-Oberto, R. R. Chianelli, J. Rios, J. G. Parsons and G. Gamez, J. Hazard. Mater., 2000, 80, 175.

72 P. X. Sheng, Y. P. Ting, J. P. Chen and L. Hong, J. Colloid Interface Sci., 2004, 275, 131.

73 V. Murphy, S. A. M. Tofail, H. Hughes and P. McLoughlin, Chem. Eng. J., 2009, 148, 425.

74 D. Chauhan, J. Dwivedi and N. Sankararamakrishnan, $R S C$ Adv., 2014, 4, 54694.

75 N. Sankararamakrishnan, A. Dixit, L. Iyengar and R. Sanghi, Bioresour. Technol., 2006, 97, 2377.

76 S. S. Banerjee and D. H. Chen, J. Hazard. Mater., 2007, 147, 792. 